\title{
The Role of Computed Cranial Tomography (CT) in Epilepsy
}

\author{
A. Guberman
}

SUMMARY: To evaluate the usefulness of CT in detecting unexpected brain lesions in epileptics, scan results were analyzed in a consecutive series of 196 adult epileptics in whom there was no known etiology for their seizures nor any abnormality on neurological examination. Nineteen additional epileptics, selected on the basis of an unexpected positive CT were also included for analysis.

In the consecutive series, the overall incidence of abnormal scans was $16 \%$ with the highest yield (44\%) found in patients with partial elementary seizures. Partial seizures secondarily generalized were correlated with a significantly higher CT positivity than purely partial seizures. Patients with seizures for less than six months more frequently showed CT abnormalities than patients with a longer history.

In 25 of 51 cases with abnormal scans a specific lesion amenable to therapy was detected, including 16 neoplasms and 5 arteriovenous malformations. Other lesions included generalized or focal atrophy, infarcts, calcified lesions of tuberous sclerosis, unexplained calcifications and focal low-density or enhancing lesions.

RÉSUMÉ: Afin d'évaluer l'utilité de la tomodensitométrie (CT) dans la détection de lésions imprévues chez l'épileptique, nous avons étudié les résultats de ce test dans une série de 196 cas d'épilepsie consécutifs chez des adultes pour lesquels on ne connaissait ni l'étiologie de l'épilepsie ni la présence d'anomalies à l'examen neurologique. Nous avons également inclus 19 sujets épileptiques chez qui un CT positif imprévu avait été trouvé.

Pour la série complète, l'incidence globale de CT anormaux fut de $16 \%$, grimpant à $44 \%$ chez les patients avec crises partielles, surtout si des dernières étaient suivies de crises généralisées. Les anomalies de tomodensitométrie sont plus fréquentes chez les patients dont les crises datent de moins de 6 mois, par rapport à ceux avec une plus longue histoire.

Chez 25 des 51 CT anormaux il fut possible d'identifier une lésion traitable, dont 16 néoplames et 5 malformations artério-veineuses. Les autres lésions traitables incluaient de l'atrophie focale, des infarctus, des lésions calcifiées de sclérose tubéreuse, des calcifications inexpliquées et d'autres lésions focales imprécises.

Can. J. Neurol. Sci. 1983; 10:16-21

Results of CT applied to large series of mixed epileptic patients, have been positive in about $50 \%$ of cases (So and Penry, 1981). Several variables, which are often not specified in published studies, would be expected to influence the CT yield in epileptics. Furthermore, CT findings whether or not they are etiologically related to epilepsy are often lumped together for analysis. For these reasons the true usefulness of this technique and clear-cut indications for its use in epilepsy have not yet been well-defined. A review of CT findings in a series of epileptic patients, in whom there was no known etiology for their seizures or other reasons besides epilepsy to suspect a CT abnormality, was undertaken in order to assess the contribution of this technique to etiological diagnosis in epilepsy.

\section{METHODS}

The study population consisted of a selected consecutive series of 196 adult epileptic patients, referred to an epilepsy clinic and neurology out-patient department in whom CT was performed (Group I). One child aged 13, previously reported (Guberman and Jaworski, 1979) was included in this group. An additional 19 cases, not part of the consecutive series, were added to the study on the basis of an abnormal CT (Group II). Patients were selected according to the following criteria.
1. A definite diagnosis of one or more epileptic seizures on clinical and EEG grounds.

2. No known definite etiology of the epilepsy prior to CT such as head trauma, birth hypoxia or trauma, meningitis, intracranial surgery, cerebrovascular disease, etc.

3. No mental retardation or abnormalities on neurological examination.

4. No history of alcoholism.

5. No obvious skull deformity.

All scans were done with contrast enhancement on an EMI machine with a $160 \times 160$ matrix using standard scanning procedures. The films were interpreted by a neuroradiologist and all abnormal films were also reviewed by the author. Equivocal or borderline abnormalities were excluded and, in particular, atrophy was diagnosed only if moderate or severe. In all cases tumors and arteriovenous malformations were confirmed by angiography and/or operation.

\section{RESULTS}

Incidence of CT abnormalities related to seizure type

Table 1 shows the incidence of CT abnormalities related to seizure type. Not unexpectedly, the highest incidence (44\%) of abnormal scans was found in patients with partial elementary seizures and the lowest incidence $(0 \%)$ in

From the Ottawa General Hospital, University of Ottawa, Ottawa, Ontario.

Received July 29, 1982. Accepted for publication October 24, 1982.

Address reprint requests to A. Guberman, M.D., F.R.C.P. (C), Division of Neurology, Ottawa General Hospital, 501 Smyth Road, Ottawa,

Ontario, Canada K1 H 8 L6. 
TABLE 1

Incidence of CT abnormality related to seizure type in 196 consecutive cases (Group 1)

\begin{tabular}{|c|c|c|c|c|c|}
\hline & \multicolumn{4}{|c|}{ Seizure type } & \multirow[t]{2}{*}{ Total } \\
\hline & \multirow{2}{*}{$\begin{array}{l}\text { Generalized } \\
\text { tonic-clonic }\end{array}$} & \multicolumn{3}{|c|}{ Partial } & \\
\hline & & Absence & Complex & Elementary & \\
\hline$C T^{\text {Normal }}$ & 54 & 5 & $\begin{array}{c}95 \\
(35)^{*}\end{array}$ & $\begin{array}{l}10 \\
(7)\end{array}$ & 164 \\
\hline Abnormal & 6 & 0 & $\begin{array}{c}18 \\
(15)\end{array}$ & $\begin{array}{c}8 \\
(6)\end{array}$ & 32 \\
\hline$\%$ Abnormal & $10 \%$ & $0 \%$ & $16 \%$ & $44 \%$ & $16 \%$ \\
\hline Total & 60 & 5 & 113 & 18 & 196 \\
\hline
\end{tabular}

*Figures in brackets represent number of cases with secondarily generalized seizures.

patients with generalized absences. CT was positive in $33 \%$ of patients with partial seizures who also had secondarily generalized seizures as opposed to only $7 \%$ in those with partial seizures alone. Thirteen of our sixteen tumor patients were affected by partial and secondarily generalized seizures.

\section{Incidence of CT abnormalities related to duration of} epilepsy

In Group I 9/25 (36\%) of cases with seizures for 6 months or less and $23 / 171(13 \%)$ of cases with epilepsy of longer duration showed CT abnormalities. In 5/9 recentonset cases and 16/23 longstanding cases the abnormality was thought to be definitely etiologically related to the epilepsy and 8 neoplasms were represented. In the overall

TABLE 2

CT abnormalities related to seizure duration $(\mathrm{N}=51)$

\begin{tabular}{lcc}
\hline & $\begin{array}{c}\text { Seizures } \\
<\mathbf{6} \text { mo. }\end{array}$ & $\begin{array}{c}\text { Seizures } \\
>\mathbf{6} \text { mo. }\end{array}$ \\
\hline $\begin{array}{l}\text { Atrophy } \\
\quad \text { Generalized }\end{array}$ & 2 & 7 \\
$\quad$ Focal or lateralized & & 5 \\
Neoplasms & 11 & 5 \\
Arachnoid cyst & & 1 \\
Calcifications & & \\
$\quad$ Basal ganglia and bifrontal \\
$\quad$ pseudohypoparathyroidism) & 1 & 1 \\
$\quad$ Tuberous sclerosis & & 1 \\
$\quad$ Unexplained & 1 & 1 \\
AVM & 1 & 4 \\
Infarct & & 2 \\
Hydrocephalus & 1 & \\
Focal lesions, unexplained & & \\
$\quad$ Low-density & 2 & 3 \\
$\quad$ Contrast-enhancing & 1 & 1 \\
\hline
\end{tabular}

group with abnormal scans $(\mathrm{N}=51) 5$ patients had a single seizure, and of those with more than 1 seizure, 15 had had epilepsy less than 6 months and 3 had had epilepsy over 6 months.

\section{Nature of CT abnormalities}

Tables 2 and 3 show the CT abnormalities in the overall series (Groups I and II) related to seizure duration and seizure type (partial with or without secondary generalization versus generalized only). In 39 of 51 cases the CT abnormality was thought to be etiologically related to the seizures and in 25 of these cases the finding on CT led to a surgical or specific medical (eg. correction of hypocalcemia) treatment. It is of note that patients with neoplasms tended to have a shorter history of epilepsy and much greater

TABLE 3

$C T$ findings related to seizure type

$(\mathrm{N}=51)$

\begin{tabular}{|c|c|c|}
\hline & $\begin{array}{c}\text { Partial } \pm \\
\text { secondarily G } \\
\text { generalized } \\
\text { seizures } \\
\end{array}$ & $\begin{array}{l}\text { Seneralized } \\
\text { seizures } \\
\text { only } \\
\end{array}$ \\
\hline \multicolumn{3}{|l|}{ Atrophy } \\
\hline Generalized & 7 & 2 \\
\hline Focal or lateralized & 4 & 1 \\
\hline Neoplasms & 14 & 2 \\
\hline Arachnoid cyst & 1 & \\
\hline \multicolumn{3}{|l|}{ Calcifications } \\
\hline $\begin{array}{l}\text { Basal ganglia and bifrontal } \\
\text { (pseudohypoparathyroidism) }\end{array}$ & 1 & 1 \\
\hline Tuberous sclerosis & 1 & \\
\hline Unexplained & 1 & 1 \\
\hline Arteriovenous malformation & 3 & 2 \\
\hline Infarct & 2 & \\
\hline Hydrocephalus & & 1 \\
\hline \multicolumn{3}{|l|}{ Focal lesions, unexplained } \\
\hline Low-density & 4 & 1 \\
\hline Contrast-enhancing & 2 & \\
\hline
\end{tabular}




\section{TABLE 4}

Neoplasms with epilepsy as only sign, detected by $C T$ $(\mathrm{N}=16)$

\section{Tumor type}

Tumor location

Low-grade glioma $3+1$ probable

Frontal

Right

Malignant astrocytoma $2+1$ probable

Left

Cavernous hemangioma 3

Temporal

$\begin{array}{llll}\text { Oligodendroglioma } & 2 & \text { Right } & 2 \\ \text { Left } & 2\end{array}$

Meningioma

1

Parietal, parasagittal 1

Schwannoma

1

Epidermoid

1

Metastatic

1

\section{Seizure type}

Adversive + generalized tonic-clonic

Other partial elementary + generalized tonic-clonic

Complex partial + generalized tonic-clonic

Complex partial

Generalized tonic-clonic

1
2

11
5

(1 yr, 3 yr, 4 yr, 5 yr, 6 yr)

Duration of epilepsy

Less than 6 months

Greater than 6 months

tendency to have partial seizures. In Tables 4 and 5 more details are given concerning the tumor and arteriovenous malformation groups. There was a strong tendency for these space-occupying lesions presenting with epilepsy to be located in fronto-temporal areas. Figures 1-3 show illustrative case examples.

\section{DISCUSSION}

In any study of CT findings in epilepsy the following factors would be expected to influence the results: (1) patient population selection variables (eg. age distribution, inclusion of patients with known seizure etiologies or evidence of brain damage by history or examination, strictness of diagnostic criteria for epilepsy), (2) seizure-related variables (eg. duration of epilepsy, seizure type), (3) CT-related variables (eg. resolution of scanner, scanning technique, use of contrast enhancement, experience of scan interpreter and criteria for reading abnormalities such as atrophy). In the present study a deliberate attempt was made to take these variables into account and to select our patients so that the resulting CT abnormalities would not be expected for any other reason except epilepsy. This approach has allowed an assessment of the true value of $\mathrm{CT}$ in unearthing etiologically-important and therapeutically relevant information in a large group of epileptic patients studied prospectively.

Our overall proportion of abnormal CT scans (16\%) was low by comparison with most other studies including adults with both partial and generalized seizures where CT yields have ranged between $40 \%$ and $50 \%$ (Gastaut et al., 1976;
TABLE 5

Arteriovenous malformations presenting with epilepsy, detected by $C T$

$$
(\mathrm{N}=5)
$$

\section{Location}

$\begin{array}{ll}\text { Right frontal } & 2 \\ \text { Left frontal } & 1 \\ \text { Left temporo-parietal } & 2\end{array}$

\section{Seizure type}

Generalized tonic-clonic

Complex partial + generalized tonic-clonic

Complex partial

Partial elementary + generalized tonic-clonic

Duration of epilepsy

1 month, 8 yr, 9 yr, 11 yr, 24 yr

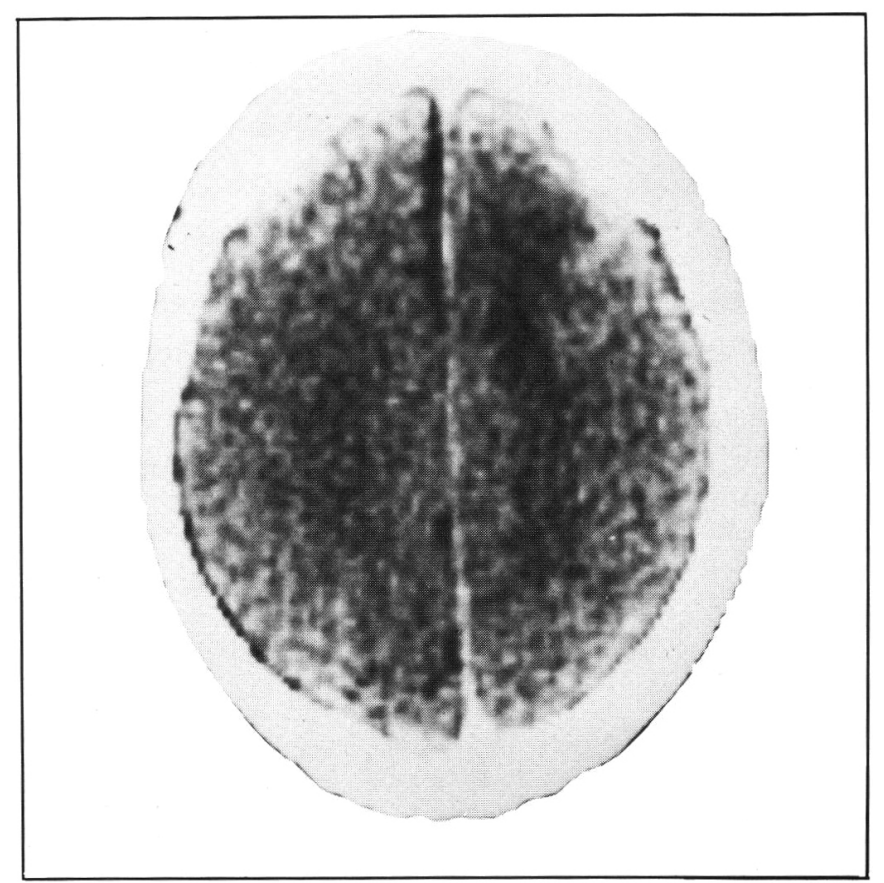

Figure I - CT scan from a 35 year-old teacher with a 3-year history of left adversive seizures at times followed by a generalized tonic-clonic seizure. Scan shows a low-density lesion in the right frontal area which at operation proved to be a widely infiltrating oligodendroglioma.

Ghazy et al., 1978; Glotzner et al., 1980; Janz, 1978; Ladurner et al., 1980; McGahan et al., 1979). This discrepancy may be readily explained by our patient selection factors and the exclusion of all but the most definite cases of atrophy. The strong relationship of CT positivity to seizure type was reflected by a $44 \%$ incidence of abnormal scans in partial elementary seizures and also by the finding of partial seizures with or without generalization in $80 \%$ of the 51 patients with abnormal scans in Groups I and II. The importance of seizure type as a predictor of CT abnormalities has been confirmed by others (So and Penry, 1980). The highest incidences of CT lesions have occurred in partial seizures, especially elementary (Angeleri et al., 1980; Bauer 


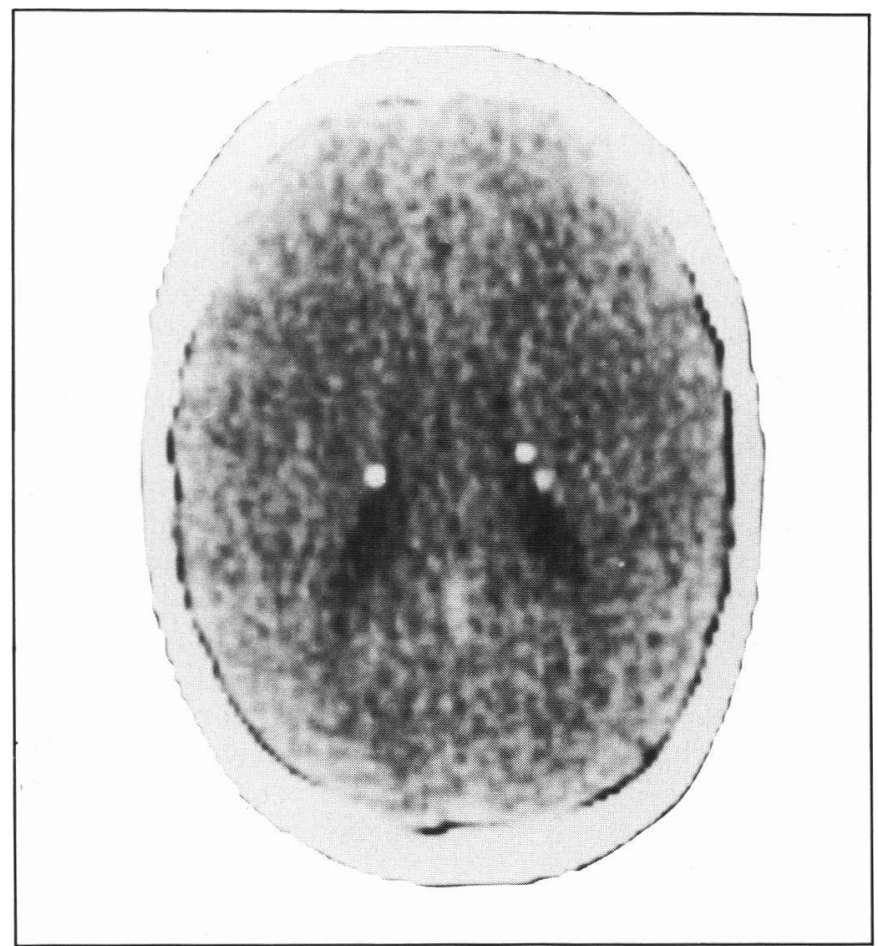

Figure $2-\mathrm{CT}$ scan from a 28 year-old student with a history of complex partial and generalized tonic-clonic seizures since age 8. Scan shows typical subependymal calcified nodules of tuberous sclerosis.

et al., 1980; Ghazy et al., 1978; Janz, 1978; Yang et al., 1979) and in the Lennox-Gastaut and West syndromes (Gastaut et al., 1976; Gastaut et al., 1978; Zimmerman et al., 1977). Angeleri et al. (1980) as opposed to most other authors, did not find a difference between CT pick-up in complex partial seizures (73\%) and partial elementary seizures (72\%) although tumors and arteriovenous malformations were proportionally three times as common in the latter group. Data from some other studies have supported our finding that partial seizures with secondary generalization are much more likely to be correlated with CT abnormalities than strictly partial seizures (McGahan et al., 1979) although others have found an equal incidence (Scolo-Lavizzari and Balmer, 1980).

Our finding of a higher incidence of CT abnormalities (36\% versus $13 \%$ ) in patients with a short (less than 6 months) history of epilepsy has been found by other authors (Angeleri et al., 1980; McGahan et al., 1979). These results may be explained in part by our original selection criteria. Patients with progressive lesions such as tumors which would be likely to show up on CT scan if their epilepsy was of long duration, would also be more likely to show other neurological signs or symptoms and therefore would have been excluded from our study. Although we have not specifically considered the question in the present study, others have found a much higher incidence of CT abnormality in late-onset (greater than age 20 or 30 ) epilepsy than in earlier onset epilepsy (Janz, 1978; Pritchard and Hungerford, 1979). Since late-onset epilepsy is likely to be of shorter duration, more likely to come to the attention of a specialty clinic, more likely to present partial seizures and more likely to harbor an underlying neoplasm or other focal lesion, these results are not unexpected.
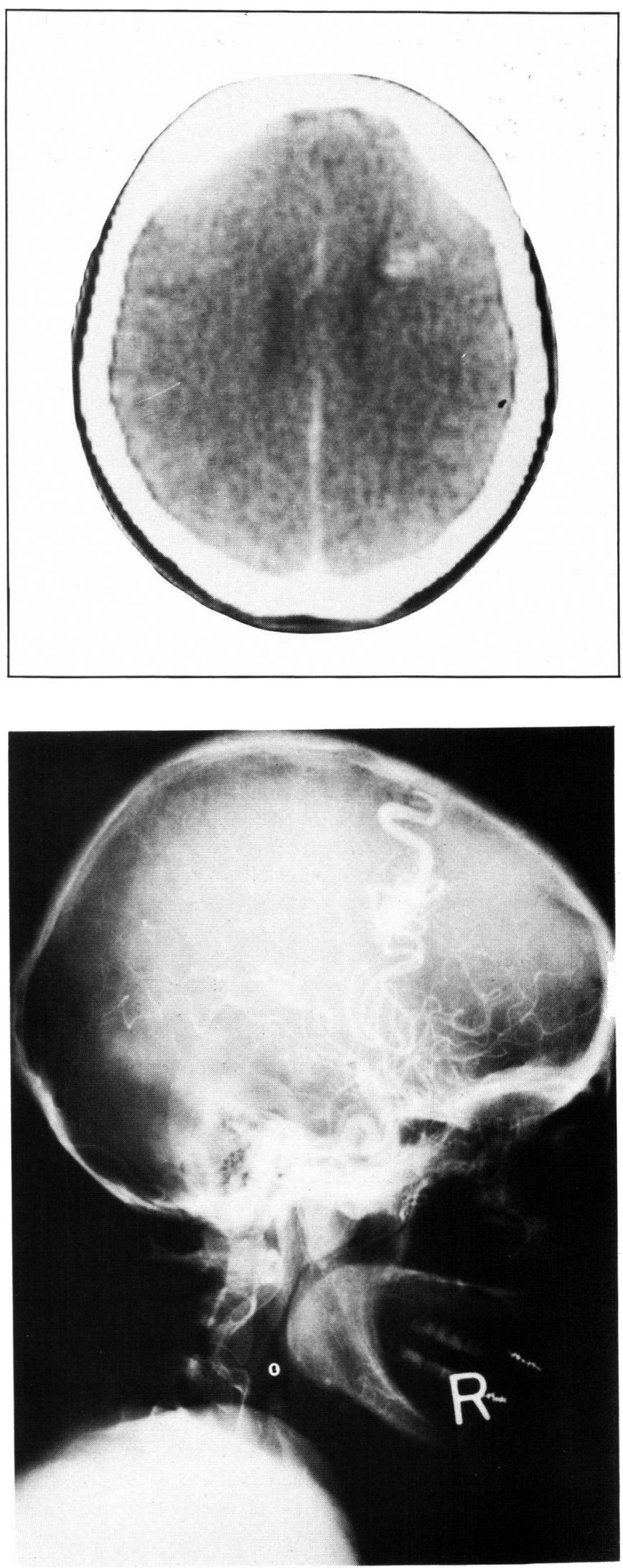

Figure 3 - Radiologic studies from a 48 year-old woman with a 24 -year history of seizures consisting of left facial twitching followed by $a$, secondarily generalized tonic-clonic seizure. (a) CT scan shows a right frontal low-density lesion with some enhancement. (b) Angiography reveals an arteriovenous malformation. 
The true value of CT scanning in epilepsy lies in its ability to detect specific unexpected lesions etiologically related to the patient's epilepsy, especially when they are potentially treatable as occurred in 21/196 of our cases in Group I. Tumors, found in $4 \%$ of our consecutive series, have been seen in 4 to $12 \%$ of cases in other series (Angeleri et al., 1980; Bauer et al., 1980; Gastaut et al., 1976; Ghazy et al., 1978; Janz, 1978; Ladurner et al., 1979; McGahan et al., 1979). In $3 \%$ of Gastaut's (1976) 500 cases, as in all of our cases, the tumor was unexpected since there were no symptoms other than epilepsy and the neurological examination was normal. The ability of a CT scan to detect occult neoplasms has been well demonstrated in our study where 16 tumors overall were found. In 8 of 13 tumor cases where angiography was done, there were no abnormalities detected despite the fact that the CT localization was already known. The tumors have for the most part represented benign lesions such as meningiomas or, less commonly, slow growing gliomas, metastatic lesions or glioblastomas. A predilection for frontal-temporal areas probably reflects the greater epileptogenicity of these regions. Our findings and those of others (Seifi et al., 1978) have emphasized the fact that a long history of epilepsy and a negative neurological examination do not rule out an underlying tumor. Arteriovenous malformations, tuberous sclerosis and pseudo-hypoparathyroidism were other specific unexpected etiological diagnoses uncovered by CT scanning in our series. The value of $\mathrm{CT}$ in diagnosing arteriovenous malformations (Leblanc et al., 1979; Kramer and Wing, 1977), subependymal calcified hamartomatous lesions of tuberous sclerosis (Gomez et al., 1975; Yang et al., 1979) and other intracranial calcifications (Guberman \& Jaworski, 1979) has been demonstrated.

An advantage of the CT is that it allows lesions to be followed serially over time with little discomfort to the patient. One of our cases showed a discrete cystic left frontal lesion which was stable over three years on CT and thought to be benign. When the seizures escaped control and the patient developed a postictal right hemiparesis and aphasia, a repeat scan showed a large glioblastoma in the area of the previous "benign" cyst.

The CT in epilepsy may also elucidate morphological features possibly resulting from repeated epileptic seizures or related to other effects of longstanding epilepsy such as drug intake. Although its mechanism is still unknown, generalized atrophy, relatively common in most series of epileptic patients, might conceivably arise as a consequence of epileptic seizures or their treatment.

Another use of the CT scan with epilepsy was described by Oakley et al., (1979) in patients without clear-cut morphological findings. By comparing CT numbers on enhanced scans between homologous areas of both hemispheres, these authors showed a slightly increased density on the side of the interictal EEG focus, thereby confirming electrical lateralization in potentially operable patients.

Despite the demonstrated usefulness of the CT in epileptic patients, some limitations remain. The orbitofrontal and temporobasal areas are notoriously difficult to image because of their proximity to bone, and it is in these regions that the pathology occurs in many cases with com- plex partial seizures. Furthermore, mesial temporal sclerosis, the most common lesion seen pathologically in patients with complex partial seizures as well as other small lesions, are beyond the resolution of present CT machines. These limitations are now being partially overcome by higher resolution scanners with the capability of obtaining views in several planes. Recently the positron emission tomographic technique, which looks at regional metabolism rather than morphology, has been shown to be capable of providing additional localizing information in epileptics with negative CT scans (Engel et al., 1981). Furthermore, some CT lesions in epileptics, although they represent morphological correlates of seizure disorders, may carry no etiologic or therapeutic implications and may merely reflect the epileptic tendency toward head injury or repeated bouts of cerebral hypoxia.

On the basis of the present study and previously reported results, it is recommended that all epileptic patients without an obvious etiology for their epilepsy, except possibly those with absence seizures, should have an enhanced CT scan. Obtaining a CT is most important in patients with recentonset, partial or poorly controlled seizures.

\section{REFERENCES}

Angeleri, F., Provinciali, L., Salvolini, U. (1980). Computerized tomography in partial epilepsy. In: Canger, R., Angeleri, F., Penry, J.K., eds., Advances in Epileptology, XIth Epilepsy International Symposium, New York, Raven Press, 53-64.

Bauer, G., Mayr, U., Pallua, A. (1980). Computerized axial tomography in chronic partial epilepsies. Epilepsia 21, 227-233.

Bogdanoff, B.M., Stafford, C.R., Green, L., Gonzales, C.F. (1975). Computerized transaxial tomography in the evaluation of patients with focal epilepsy. Neurology 25 , 1013-1017.

Engel, J. Jr., Rausch, R., Lieb, J.P., Kuhl, D.E., Crandall, P.H. (1981). Correlation of criteria used for localizing epileptic foci in patients considered for surgical therapy of epilepsy. Ann Neurol 9, 215-224.

Gastaut, H., Gastaut, J.L., Regis, H., Raybaud, C., Farnarier, P., Michotey, P., Michel, B. (1976). Etude des épilepsies par la tomographie axiale transverse de l'encéphale commandée par ordinateur. Nouv Presse Méd 5, 481-486.

Gastaut, H., Gastaut, J.L., Regis, H., Bernard, R., Pinsard, N., Saint-Jean, M., Roger, J., Dravet, C. (1978). Computerized tomography in the study of West's syndrome. Devel. Med. Child. Neurol 20, 21-27.

Ghazy, A., Slettnes, O., Lundervold, A. (1978). Electroencephalography and computerized transaxial tomography in epilepsy diagnosis. Clin. Electroencephal. 9, 159-169.

Glotzner, F.L., Geiser, R., Ratzka, M. (1980). Correlations between computerized tomography, EEG and clinical findings in patients with seizures. In: Lechner, H., Aranibar, A., eds., EEG and Clinical NeurophysiologyProceedings of the 2nd European Congress of EEG and Clinical Neurophysiology, Salzburg, Austria, September 16-19, 1979, Amsterdam, Excerpta Medica, 32-36. 
Gomez, M.R., Mellinger, J.F., Reese, D.F. (1975). The use of computerized transaxial tomography in the diagnosis of tuberous sclerosis. Mayo Clin. Proc. 50, 553-556.

Guberman, A., Jaworski, Z.F.G. (1979). Pseudohypoparathyroidism and epilepsy: Diagnostic value of computerized cranial tomography. Epilepsia 20, 541-553.

Janz, D. (1978). Morphological diagnosis in epilepsy by computer assisted brain tomography. In: Meinardi, H., Rowan, A.J., eds., Advances in Epileptology - 1977, Amsterdam, Swetz \& Zeitlinger, 376-384.

Kramer, R.A., Wing, S.D. (1977). Computed tomography of angiographically occult cerebral vascular malformations. Radiology 123, 649-652.

Ladurner, G., Martischnig, R., Aranibar, A., Mohsen, M.J., Sager, W.D., Lechner, H. (1980). The value of CT and EEG in the diagnosis of epilepsy. In: Lechner $H$., Aranibar, A., eds., EEG and Clinical Neurophysiology Proceedings of the 2nd European Congress of EEG and Clinical Neurophysiology, Salzburg, Austria September 16-19, 1979, Amsterdam, Excerpta Medica, 3-10.

Leblanc, R., Ethier, R., Little, J.R. (1979). Computerized tomography findings in arteriovenous malformations of the brain. J. Neurosurg. 51, 765-772.

McGahan, J.P., Dublin, A.B., Hill, R.P. (1979). The evaluation of seizure disorders by computerized tomography. J. Neurosurg. 50, 328-332.

Oakley, J., Ojemann, G.A., Ojemann, L.M., Cromwell, L. (1979). Identifying epileptic foci on contrast-enhanced computerized tomographic scans. Arch. Neurol. 36, 669671.

Pritchard, P.B., Hungerford, G.D. Computerized tomography in temporal lobe epilepsy: electroanatomical correlates. Presented at The Meeting of the Eastern Association of Electroencephalographers, New York, Dec. 4, 1979.

Scollo-Lavizzari, G., Balmer, C. (1980). EEG and computerized transaxial tomography in patients with temporal lobe epilepsy. In: Lechner, H., Aranibar, A., eds., EEG and clinical Neurophysiology-Proceedings of the 2nd European Congress of EEG and Clinical Neurophysiology, Salzburg, Austria, September 16-19, 1979, Amsterdam, Excerpta Medica, 11-15.

Seifi, J., Boulos, R.S., Teasdall, R.D. (1978). Seizures and brain tumor in neurologically intact adult patients: Role of computerized tomography (CT scan). Henry Ford Hosp. Med. J. 26, 18-21.

So, E.L., Penry, J.K. (1981). Epilepsy in adults. Ann. Neurol. 9, 3-16.

Yang, P.J., Berger, P.E., Cohen, M.E., Duffner, P.K. (1979). Computed tomography and childhood seizure disorders. Neurology 29, 1084-1088.

Zimmerman, A.W., Niedermeyer, E., Hodges, F.J. (1977). Lennox-Gastaut syndrome and computerized axial tomography findings. Epilepsia 18,463-464. 